\title{
The Relationship between Postgraduates' Academic Procrastination and Psychodynamic Variables
}

\author{
Naiyi Wang ${ }^{1}$, Ping $\mathrm{He}^{2}$ and Qian $\mathrm{Li}^{1}$ \\ ${ }^{1}$ Institute of Educational Psychology and School Counseling, Beijing Normal University, Beijing, China \\ ${ }^{2}$ Zhuhai Special Education School, Zhuhai, P.R.China \\ wangnaiyi@bnu.edu.cn
}

\begin{abstract}
Academic procrastination refers to the tendency to procrastinate academic tasks, and the concomitant negative emotions. Based on questionnaire surveys of 305 postgraduate students, the study investigated the relationship between academic procrastination and three psychodynamic variables- achievement motivation, goal orientation and academic self-efficacy through path analyses. Main results included: (1) Academic procrastination is a common phenomenon among the postgraduates, nearly $60 \%$ of them having the procrastination tendency, while almost all of them having the desire to reduce procrastination. The female postgraduates showed a higher level of academic procrastination than the male postgraduates. (2) Academic procrastination level is correlated with different dimensions of the three psychodynamic variables. (3) The psychodynamic variables contribute to academic procrastination level by three ways. First, achievement motivation, goal orientation, and academic self-efficacy directly contribute to academic procrastination negatively. Second, goal orientation and academic self-efficacy contribute to academic procrastination through achievement motivation. Third, goal orientation contributes to achievement motivation through academic self-efficacy, which then contributes to academic procrastination. Achievement motivation may act as a mediating factor. Implications for educators were discussed based on these findings.

Index Terms - academic procrastination, achievement motivation, goal orientation, academic self-efficacy
\end{abstract}

\section{Introduction}

We all had this experience once, in which an academic task could not be completed according to the established plan, but had to be put off again and again. Finally, either the result quality was greatly reduced, or the task was pending forever. A series of negative emotions such as stress and anxiety were triggered during the course of delay. In the field of educational psychology, this phenomenon is called "academic procrastination" [1]. It has been shown that academic procrastination is common among students. Constant procrastinations will not only impair students' academic performances, but also induce anxiety, put students under pressure, and jeopardize their physical and mental health [2].

There are various views concerning the cause of academic procrastination. Most of them agreed that academic procrastination is a motivation issue [3], on which psychodynamic factors such as achievement motivation, goal orientation and self-efficacy show the greatest impacts. Achievement motivation is an internal driving force that makes people be willing to do things in line with people's own values, and strive to succeed. It is an important part of individual psychological dynamics, and consists of two subcomponents: motivation to pursue success and motivation to avoid failure. Fear of failure is an important factor predicting procrastination. Goal orientation refers to the goal preference when an individual carrying out a task. It is a qualitative motivation concept rather than a quantitative one. Generally, it is divided into three subcomponents: taskinvolved orientation, prove ego-involved orientation and avoid ego-involved orientation. Academic self-efficacy is a subjective judgment of one's own ability of controlling learning behaviour and academic performance. According to social cognitive theory, self-efficacy affects students' task choice, diligence degree and learning persistence. Selfefficacy directly determines the level of individual's motivation. Hence, the psychodynamic variables in the present study were defined as mental factors that influence or determine the level and direction of individual achievement behaviour, including achievement motivation, goal orientation and academic self-efficacy.

Previous studies on academic procrastination mainly focused on college students. Compared with undergraduate students, postgraduates have more difficult and self-directed learning tasks, and more flexible study time. Accordingly, postgraduates may have higher levels of academic procrastination, which was confirmed by a previous study [4]. However, researches on postgraduates' academic procrastination are relatively scanty. Hence, this study aimed at investigating the relationship between academic procrastination and three psychodynamic variables: achievement motivation, goal orientation, and academic selfefficacy of postgraduates. Using path analyses, the ways by which the three psychodynamic variables contribute to academic procrastination were explored. The results provided a theoretical basis for future intervention studies on postgraduates' academic procrastination.

\section{Method}

\section{A. Participants}

Three hundred and five fresh master degree holders of 2012 participated in the study (138 males). They were from Beijing Normal University and Beijing University of Posts and Telecommunications.

\section{B. Measures}

1) Academic Procrastination Scale: Academic procrastination was measured by the first part of the Graduate Academic Procrastination Scale developed and revised by $\mathrm{C}$. $\mathrm{Hu}$ (2008), based on the Procrastination Assessment Scale for 
Students (PASS) by Solomon and Rothblum. It consisted of 18 items concerning six typical academic activities of postgraduates: reading literatures, searching for information, preparing for exams, completing tasks assigned by supervisors, writing the thesis proposal, publishing papers, and writing the thesis. For each academic activity, the first two items measured the level of procrastination, and the third item measured the desire of reducing procrastination.

2) Achievement Motivation Scale: The scale was originally developed by T. Nygard, and revised by R. Ye. It consisted of two subscales: one on the motivation to pursue success, the other on the motivation to avoid failure. Each subscale included 15 items. The final score of achievement motivation was the difference between the score of the motivation to pursue success and the score of the motivation to avoid failure. The higher the final score, the stronger is the achievement motivation.

3) Goal Orientation Scale: The scale consisted of three subscales: task-involved orientation (4 items), prove egoinvolved orientation (4 items), and avoid ego-involved orientation (6 items).

4) Academic Self-Efficacy Scale: The scale was developed and revised by C. Hu (2008). It included nine items.

\section{Procedure and Data analyses}

Students completed the four scales. Excel2007 and SPSS17.0 were used for data processing and analyses.

\section{Results}

A. The level of academic procrastination and the desire to reduce it

For the 305 postgraduate students surveyed, $57.71 \%$ of them reported procrastination of different levels, $18.69 \%$ of them having a high level of procrastination, i.e., always procrastinate (Table 1 ). Only $2.60 \%$ of them never want to reduce academic procrastination, while the vast majority of them always or occasionally want to reduce it (Table 2). Independent samples T-test was carried out to examine the gender difference. The results showed that female postgraduates had a higher level of academic procrastination than their male counterparts $(p<.05)$; no significant gender difference was found in the desire to reduce academic procrastination (Table 3 ).

TABLE 1 Level of academic procrastination of postgraduates

\begin{tabular}{|l|c|c|}
\hline & $\mathrm{N}$ & Percent $(\%)$ \\
\hline Always procrastinate & 27 & 18.69 \\
Occasionally procrastinate & 134 & 39.02 \\
\hline Never procrastinate & 144 & 42.29 \\
\hline
\end{tabular}

TABLE 2 Desire to reduce academic procrastination of postgraduates

\begin{tabular}{|l|c|c|}
\hline & $\mathrm{N}$ & Percent (\%) \\
\hline Always want to & 80 & 26.20 \\
Occasionally want to & 217 & 71.20 \\
\hline Never want to & 8 & 2.60 \\
\hline
\end{tabular}

TABLE 3 Comparisons between male and female postgraduates on the level of academic procrastination and desire to reduce it $(\mathrm{M} \pm \mathrm{SD})$

\begin{tabular}{|c|c|c|}
\hline & Procrastination level & Desire to reduce \\
\hline Male & $35.47 \pm 8.13$ & $21.11 \pm 5.11$ \\
Female & $37.38 \pm 8.06$ & $20.89 \pm 5.27$ \\
\hline $\mathrm{T}$ & $-2.133^{*}$ & 0.150 \\
\hline
\end{tabular}

Note: $* p<.05$

\section{B. Correlation analyses}

As shown in Table 4, the level of academic procrastination was positively correlated with avoid egoinvolved orientation and motivation to avoid failure, and negatively correlated with motivation to pursue success and academic self-efficacy. The desire to reduce academic procrastinations was positively correlated with motivation to avoid failure, and negatively correlated with academic selfefficacy.

TABLE 4 The correlations between academic procrastination and different dimensions of the three psychodynamic variables

\begin{tabular}{|c|c|c|}
\hline & Procrastination level & Desire to reduce \\
\hline TO & -.071 & .077 \\
\hline PEO & -.012 & .031 \\
\hline AEO & $.137^{*}$ & -.028 \\
\hline MPS & $-.457^{* *}$ & .027 \\
\hline MAF & $.166^{*}$ & $.149^{*}$ \\
\hline ASE & $-.356^{* *}$ & $-.126^{*}$ \\
\hline
\end{tabular}

Note: $* p<.05, * * p<.01$. TO=Task-involved orientation; PEO=Prove egoinvolved orientation; $\mathrm{AEO}=\mathrm{Avoid}$ ego-involved orientation; MPS=Motivation to pursue success; MAF= Motivation to avoid failure; ASE=Academic self-efficacy.

\section{Regression analyses}

The effects of different dimensions of achievement motivation, goal orientation and academic self-efficacy on academic procrastination level were tested using multiple regression analyses (Stepwise method). The results showed that four predictor variables significantly predict academic procrastination level, i.e., motivation to pursue success, academic self-efficacy, motivation to avoid failure, and avoid ego-involved orientation (Table 5).

Among the four predictor variables, motivation to pursue success had the strongest prediction power for academic procrastination level, accounting for $20.9 \%$ of its total variance. The latter three variables accounted for $1.2 \%, 1.1 \%$ and $1.0 \%$ of the total variance respectively. The accumulative rate of interpretation of the four predictor variables was $24.2 \%$. Furthermore, motivation to pursue success and academic self-efficacy negatively predicted academic procrastination, while motivation to avoid failure and avoid ego-involved orientation positively predicted academic procrastination. The standardized regression equation was: Academic procrastination $=-0.399 \times$ motivation to pursue success $-0.137 \times$ academic self-efficacy $+0.110 \times$ motivation to avoid failure $+0.103 \times$ avoid ego-involved orientation. 
TABLE 5 Regression analyses for the prediction of academic procrastination from achievement motivation, goal orientation and academic self-efficacy

\begin{tabular}{|c|c|c|c|c|c|}
\hline & $\mathrm{R}$ & $\mathrm{R}^{2}$ & $\Delta \mathrm{R}^{2}$ & $\mathrm{~F}$ & $\beta$ \\
\hline MPS & .457 & .209 & .209 & $80.134 * * *$ & -.399 \\
\hline ASE & .470 & .221 & .012 & $42.758^{* * *}$ & -.137 \\
\hline MAF & .482 & .232 & .011 & $30.375^{* * *}$ & .110 \\
\hline AEO & .492 & .242 & .010 & $26.395 * * *$ & .103 \\
\hline
\end{tabular}

Note: $* * * p<.001$. Predictor variables entered the model: MPS, ASE, MAF and AEO; Dependent variable: academic procrastination level.

\section{Path analyses for the level of academic procrastination}

Using multiple regression analyses (Forced entry method), a path model was built up to examine the direct and indirect effects of achievement motivation, goal orientation and academic self-efficacy on the level of academic procrastination. In total three multiple regression analyses were conducted. For the first regression, the criterion variable was academic procrastination; the predictor variables were achievement motivation, goal orientation and academic selfefficacy. For the second regression, the criterion variable was achievement motivation; the predictor variables were goal orientation and academic self-efficacy. For the third regression, the criterion variable was academic self-efficacy, while the predictor variable was goal orientation. The path model was shown in Fig. 1.

The results of the path analyses showed that there are three ways by which the three psychodynamic variables contribute to the level of academic procrastination. Firstly, achievement motivation, goal orientation and academic self-efficacy directly contribute to academic procrastination negatively. Secondly, goal orientation and academic self-efficacy indirectly contribute to academic procrastination through achievement motivation. Thirdly, goal orientation contributes to achievement motivation through academic self-efficacy, which then contributes to academic procrastination. From these results, it was inferred that achievement motivation may be a mediating factor between psychodynamic variables and academic procrastination.

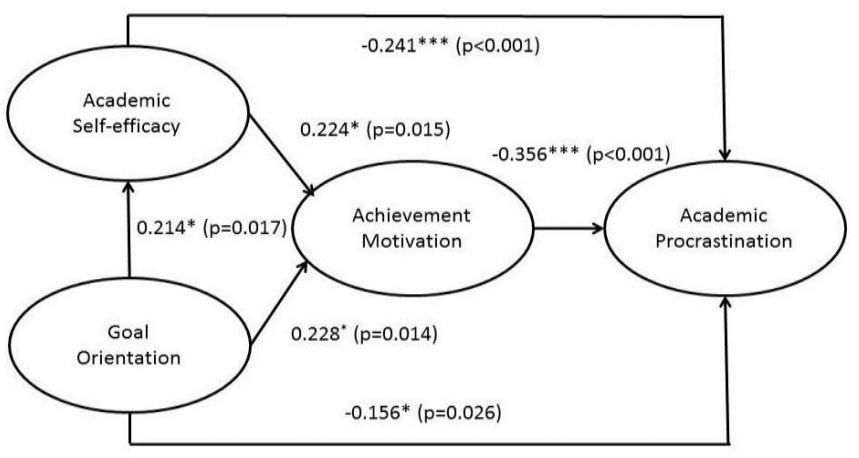

Fig. 1 The path model for academic procrastination

\section{Discussions and implications for educators}

\section{A. Postgraduates' academic procrastination and its gender difference}

This study showed that academic procrastination is a common phenomenon in postgraduates $(57.71 \%)$, but only a small part $(18.69 \%)$ of them has a high level of academic procrastination. The proportion of postgraduates with academic procrastination was slightly smaller compared to the finding of the previous study [5]. In addition, despite the fact that some of the postgraduates do not have severe academic procrastination problem, the vast majority $(97.38 \%)$ of them showed a desire to reduce procrastination. Thus it can be seen that academic procrastination is one of the difficult problems bedevilling students [5]. When it comes to the gender difference in procrastination, previous studies provided inconsistent results [6]. As shown in the present study, female postgraduates had a higher level of academic procrastination than their male counterparts. However, there was no significant gender difference in the desire of reducing academic procrastination. This may reflect the specific situation of academic procrastination of postgraduates in China nowadays.

Based on these findings, college counselling centers should pay close attention to postgraduates' academic procrastination and their strong desire of reducing the procrastination. In order to relieve academic procrastination and its concomitant negative emotions among postgraduates, college counselling centers may offer some time management lectures [7] or group counselling activities, through which postgraduates could improve both awareness and skills of selfmanagement. Besides, in view of the facts that female postgraduates have a higher level of academic procrastination and are more susceptible to negative emotions [6], colleges should pay more attention to female postgraduates' procrastination, and implement appropriate interventions according to different causes of academic procrastination between males and females [8].

\section{B. Correlations between academic procrastination and psychodynamic variables}

The results showed that motivation to pursue success was negatively correlated with individual's academic procrastination level. That is to say, when an individual pursues for success, he or she will be more actively engaged in academic tasks, and hence be less procrastinated. In contrast, the motivation to avoid failure was positively correlated with both academic procrastination level and the desire to reduce it. On the one hand, fear of failure leads people to continually procrastinate to avoid failure. On the other hand, it stimulates people's desire to extricate from academic procrastination.

Among the three types of goal orientation, avoid egoinvolved orientation was positively correlated with the level of academic procrastination, indicating that a learning goal of concealing one's unfavourable characteristics will increase the academic procrastination level. The learning behaviour of these students are stimulated and maintained by extrinsic motivation. Therefore, the intensity of their motivation and the persistence of their learning behaviour are susceptible to environmental factors, and their procrastination level is higher [9].

Academic self-efficacy showed a negative correlation with both the level of academic procrastination and the desire 
to reduce it. One with higher academic self-efficacy is more confident of his/her learning ability, tending to choose tasks that accord with one's ability level and even full of challenge. These students will respond positively in the face of difficulty, so that their academic procrastination level is lower, and their desire to reduce the procrastination is relatively lower as well. On the contrary, one with lower academic self-efficacy is less confident, and is inclined to give up easily in front of difficulty. Therefore, their procrastination level is higher, and their desire to reduce procrastination is stronger.

\section{Effects of psychodynamic variables on academic procrastination}

The results of path analyses revealed that except for direct contributions of the three psychodynamic variables, goal orientation and academic self-efficacy also indirectly contribute to academic procrastination through achievement motivation. In addition, goal orientation contributes to achievement motivation through academic self-efficacy, which then contributes to academic procrastination. The results indicated that achievement motivation may be a mediating variable. According to these results, the procrastination intervention work in colleges could start from the following points.

\section{1) Help students establish correct concepts of ability, improve their achievement motivation}

The study found that achievement motivation could directly contribute to academic procrastination. Specifically, motivation to pursue success negatively predicts the level of academic procrastination, and motivation to avoid failure positively predicts the level of academic procrastination. In addition, achievement motivation also acts as a mediating factor for the effects of goal orientation and academic selfefficacy on academic procrastination. Hence, achievement motivation may be a key factor during the interventions for academic procrastination.

On the one hand, college teachers and counsellors may improve students' motivation to pursue success by providing more positive social support and relieving students' stress. On the other hand, teachers and counsellors should help students establish correct concepts of ability, and create conditions under which each student could experience success. Thus, through practice students could learn that personal ability can be improved through efforts. In this way students' motivation to avoid failure may be reduced, accordingly their academic procrastination will be relieved.

\section{2) Cultivate students' academic self-efficacy}

Because academic self-efficacy has a close relationship with academic procrastination, teachers should cultivate students' academic self-efficacy consciously. To this end, teachers should give students timely guidance and feedback, as well as appropriate encouragement, and help them obtain successful learning experiences. Furthermore, setting examples may help students learn from each other, and enhance their academic self-efficacy from other students' successful experiences.

\section{3) Assign proper academic tasks to students, help them set up reasonable academic goals}

In general, learning goals could be divided into three classes regarding their orientations: task-involved, prove egoinvolved, and avoid ego-involved. While the former is a learning orientation, the latter two belong to the performance orientation. As for performance oriented students, their reasons for engaging in academic tasks are either to earn a certain reward (e.g., a good grade) or to avoid a punishment. In other words, they are more driven by extrinsic motivations, which may impair the intensity of their motivation and the persistence of learning behaviour, hence increase procrastination level. In order to help students adapt more task-involved orientation, teachers may provide tasks which are more meaningful and interesting to students, and less judgmental. Additionally, the influences of factors such as task difficulty [10] and deadline on academic procrastination should also be taken into account. When assigning tasks, teachers should select those with moderate difficulty and could be accomplished through efforts. Moreover, optimal task deadline should be set up by teachers. It should be neither too far away, which removes the sense of urgency and causes student procrastination, nor too close, which may bring anxiety and fear for failure and causes student procrastination as well [11].

\section{References}

[1] H. Huang, "A study on the relationship between goal orientations, selfefficacy, task-value and academic procrastination of college students," (dissertation), Northeast Normal University, 2006.

[2] C. Lay, and S. Silverman, "Trait procrastination, anxiety and dilatory behavior," Pers. Indiv. Differ., vol. 21, pp. 61-67, 1996.

[3] C. Senecal, R. Koestner, and R. J. Vallerand, "Self-regulation and academic procrastination," J. Soc. Psychol., vol. 135, pp. 607-619, 1995.

[4] J. Wang, "Comparison Analysis for Procrastination between Undergraduate and Graduate Students," (dissertation), Nanjing University of Chinese Medicine, 2009.

[5] L. J. Solomon, and E. D. Rothblum, "Academic procrastination: frequency and cognitive-behavioral correlates," J. Couns. Psychol., vol. 31, pp. 503-509, 1984.

[6] A. Feingold, "Gender differences in personality: A meta-analysis," Psychol. Bull., vol. 116, pp. 429-526, 1994.

[7] S. M. Moon, and A. J. Illingworth, "Exploring the dynamic nature of procrastination: A latent growth curve analysis of academic procrastination," Pers. Indiv. Differ., vol. 38, pp. 297-309, 2005.

[8] B. U. Ozer, A. Demir, and J. R. Ferrari, "Exploring academic procrastination among Turkish students: possible gender differences in prevalence and reasons," J. Soc. Psychol., vol. 2, pp. 247-251, 2009.

[9] C. A. Wolters, "Understanding procrastination from a self-regulated learning perspective," J. Educ. Psychol., vol. 95, pp. 179-187, 2003.

[10] E, Lee, "The Relationship of Motivation and Flow Experience to Academic Procrastination in University Students," J. Genet. Psychol., vol. 1, pp. 5-14, 2005.

[11] N. Milgram, S. Marshevsky, and C. Sadeh, "Correlates of academic procrastination: Discomfort, task aversiveness, and task capability," $J$. Psychol., vol. 2, pp. 145-155, 1995. 